\title{
Categorization in Mechanically Ventilated Pediatric Subjects: A Proposed Method to Improve Quality
}

\author{
Brian K Walsh PhD RRT-NPS RPFT AE-C FAARC, Craig D Smallwood RRT, \\ Jordan S Rettig MD, John E Thompson RRT-NPS FAARC, \\ Robert M Kacmarek PhD RRT FAARC, and John H Arnold MD
}

\begin{abstract}
BACKGROUND: Thousands of children require mechanical ventilation each year. Although mechanical ventilation is lifesaving, it is also associated with adverse events if not properly managed. The systematic implementation of evidence-based practice through the use of guidelines and protocols has been shown to mitigate risk, yet variation in care remains prevalent. Advances in health-care technology provided the ability to stream data about mechanical ventilation and therapeutic response. Through these advances, a computer system was developed to enable the coupling of physiologic and ventilation data for real-time interpretation. Our aim was to assess the feasibility and utility of a newly developed patient categorization and scoring system to objectively measure compliance with standards of care. METHODS: We retrospectively categorized the ventilation and oxygenation statuses of subjects within our pediatric ICU utilizing 15 rules-based algorithms. Targets were predetermined based on generally accepted practices. All patient categories were calculated and presented as a percent score $(0-100 \%)$ of acceptable ventilation, acceptable oxygenation, barotrauma-free, and volutrauma-free states. RESULTS: Two hundred twenty-two subjects were identified and analyzed encompassing $1,578 \mathrm{~d}$ of mechanical ventilation. Median age was $3 \mathrm{y}$, median ideal body weight was $14.7 \mathrm{~kg}$, and $63 \%$ were male. The median acceptable ventilation score was $84.6 \%$, and the median acceptable oxygenation score was $70.1 \%$ (100\% being maximally acceptable). Potential for ventilator-induced lung injury was broken into 2 components: barotrauma and volutrauma. There was very little potential for barotrauma, with a median barotrauma-free state of $100 \%$. Median potential for a volutrauma-free state was $56.1 \%$. CONCLUSIONS: We demonstrate the first patient categorization system utilizing a coordinated data-banking system and analytics to determine patient status and a surveillance of mechanical ventilation quality. Further research is needed to determine whether interventions such as visual display of variance from goal and patient categorization summaries can improve outcomes. (ClinicalTrials.gov registration NCT02184208.) Key words: computer decision support; mechanical ventilation; ventilatorinduced lung injury; quality; protocols; evidence-based practice; data. [Respir Care 2016;61(9):1168-1178. (c) 2016 Daedalus Enterprises]
\end{abstract}

\section{Introduction}

Hospitals are facing increasing pressure to improve outcomes and lower costs. The ICU, where the most critical

\footnotetext{
Mr Walsh, Smallwood, Thompson and Drs. Arnold and Rettig are affiliated with the Department of Anesthesiology, Perioperative, and Pain Medicine, Division of Critical Care Medicine, Boston Children's Hospital and Pediatric Anesthesia, Harvard Medical School, Boston, Massachusetts. Mr Smallwood is affiliated with the Department of Anesthesiology, Perioperative, and Pain Medicine, Division of Critical Care
}

and costly care is provided to the sickest patients, represents an opportunity to address both patient-specific outcomes and reduction in costs. The ICU is a complex environment where lifesaving technology, such as mechanical ventilation, is administered. By capturing and analyzing data generated in this environment, clinicians may stream-

\footnotetext{
Medicine, Boston Children's Hospital, Boston, Massachusetts. Dr Kacmarek is affiliated with the Department of Respiratory Care, Massachusetts General Hospital, Boston, Massachusetts.
} 
line and optimize care for individual patients. Individualized treatment plans based on patient continuous data can augment clinical decision-making and potentially improve outcomes.

Of the critically ill patients in the ICU, an estimated $30-50 \%$ require some type of ventilatory support. ${ }^{1}$ Respiratory disorders are the main cause of respiratory failure in children..$^{2-4}$ Although mechanical ventilation is generally lifesaving, it can be associated with adverse events if not appropriately initiated, maintained, and monitored. The systematic implementation of evidence-based practice through the use of guidelines and protocols has been shown to mitigate the risk, yet variation in care among and within institutions remains prevalent. ${ }^{5-13}$ Variation in the application of mechanical ventilation therapy may pose a significant health risk to patients by prolonging duration of ventilation and length of hospital stay and may increase the likelihood of adverse events.

When not guided by evidence-based guidelines, clinical decisions about mechanical ventilation rely heavily on intermittent manual assessments and clinical judgment often without consideration of continuously monitored pulmonary mechanics, gas exchange, and cardiopulmonary interactions or trends. Most approaches to mechanical ventilation are standardized; however, implementation and timely execution of mechanical ventilation requires knowledge and concern regarding lung protection and overall patient safety.

Mechanical ventilation has undergone significant advances over the last decade as a result of improved monitoring, more established predictors for titrating support, and better understanding of how lung injury occurs. There is evidence that adopting clinical practice guidelines together with lung-protective ventilation strategies reduces mortality in adult patients. $6,9,11,12,14$ Quality of mechanical ventilation should focus on reducing the duration of mechanical ventilation, stay, and cost of care by monitoring goal obtainment during mechanical ventilation, identifying practice variance, and liberating patients as soon as the rea-

\footnotetext{
Dr Walsh, Mr Smallwood, Dr Rettig, Mr Thompson, and Dr Arnold are on staff at Boston Children's Hospital, which owns the intellectual property and receives royalties on the sale of the T3 system. Dr Rettig, Mr Walsh, Mr Smallwood, and Dr Arnold have intellectual property surrounding the computer-aided mechanical ventilation project and have received research support from Draeger Medical. Mr Walsh has received research support from GE Healthcare. Dr Kacmarek discloses relationships with Covidien, OrangeMed, and Venner Medical.
}

Correspondence: Brian K Walsh RRT-NPS RPFT AE-C FAARC, Department of Anesthesiology, Perioperative and Pain Medicine, Division of Critical Care Medicine, Boston Children's Hospital, 300 Longwood Avenue, Bader 634, Boston, MA 02115. E-mail: briankwalsh@me.com.

DOI: $10.4187 /$ respcare. 04723

\section{QUICK LOOK}

\section{Current knowledge}

The quality of mechanical ventilation includes monitoring clinical outcomes such as length of stay, time to liberation, ventilator-free days, or ventilator-associated events. Poor outcomes are often attributed to poor compliance with standards of care. Random manual audits of intermittent assessments within the electronic medical record are used to determine variances in standard of practice but are labor-intensive and often miss opportunities to improve.

\section{What this paper contributes to our knowledge}

With the advent of computer-processed mechanical ventilation and physiologic monitors, more data are available than ever. This paper demonstrates that rules-based algorithms applied to continuous data can be utilized to categorize patient status and help determine the percentage of time a patient spends outside the standard of care.

sons for mechanical ventilation are resolved. In an effort to assist clinicians with determining their performance, we developed a system of care called computer-aided mechanical ventilation to leverage these data to determine the quality of mechanical ventilation care. A computerized method of patient status identification from continuous data is presented.

\section{Methods}

Following institutional review board approval and registration with ClinicalTrials.gov, we retrospectively analyzed subjects who required invasive mechanical ventilation within our 2 pediatric ICUs (30-bed medical/surgical ICU and 29-bed cardiac ICU). Due to the pilot nature of this study, we began a phase rollout of collecting data on mechanically ventilated patients who were anticipated to be ventilated for $>3 \mathrm{~h}$. Subjects were prospectively selected by 2 respiratory therapists in charge of the limited rollout in May of 2013. Data recording was based on the availability of connectivity equipment to a data network that stores, analyzes, and displays information dubbed the T3 (Etiometry, Boston, Massachusetts) system.

\section{Inclusion Criteria for Data Analysis}

Subjects were included through a sampling of mechanical ventilation data found within the $\mathrm{T} 3$ analytics platform for $>3 \mathrm{~h}$ within our $\mathrm{T} 3$ analytics platform. 


\section{Categorization in Mechanically Ventilated Pediatric Subjects}

\section{Exclusion Criteria for Data Analysis}

Patients were excluded for 4 reasons: (1) if the system was unavailable; (2) if the ventilator data output was not compatible with our system; (3) if the medical record number or name was not found within our electronic medical record; or (4) if alternative modes of ventilation, such as high-frequency oscillatory ventilation or airway pressure release ventilation, were used.

\section{Data Collection and Display System}

This was a prospective deployment followed by a retrospective analysis pilot study designed to demonstrate the feasibility of the system and identify strengths and weakness of the T3 data collection and analytics platform developed by the Departments of Anesthesia and Cardiology at Boston Children's Hospital. The primary functions of the T3 system are to aggregate, store, and display comprehensive real-time patient data for clinicians. The technology provides a platform to track patient data on a single, easy-to-manipulate monitoring system, viewable on standard web browsers within the hospital infrastructure. Additional functionality includes the ability to formulate and collate multivariable algorithms for research purposes. It is this analytics platform that we evaluated.

\section{Data Handling}

The computer-aided mechanical ventilation module was built upon a web-based platform for data collection developed to streamline physiologic and mechanical ventilation data collection and continuously display these data. In brief, the T3 system utilizes an FDA-cleared data collection system previously used for research endeavors.

Mechanical ventilators stream their data to our critical care bedside monitors (MP90 or MX800, Philips Healthcare, Amsterdam, Netherlands) through a proprietary data connectivity engine by the same company labeled Intellibridge, utilizing the EC-10 module and brand-specific cables. The T3 system uses the medical record number as the key identifier to request and obtain the patient's name, date of birth, and sex from the admission, discharge, transfer server all within our secure intranet infrastructure. There is one T3 server for each ICU. Nightly, the T3 ICU servers export data to a research database to allow future analysis.

The physiologic and mechanical ventilation data were combined manually with demographics and reason for mechanical ventilation from the respiratory therapy quality improvement database. The 80 reasons for mechanical ventilation were grouped into 4 general cohorts: medical, surgical, cardiac surgery, and cardiac. Ideal body weight was extracted from the electronic medical record. If data utilized in the calculation of an algorithm were not available,

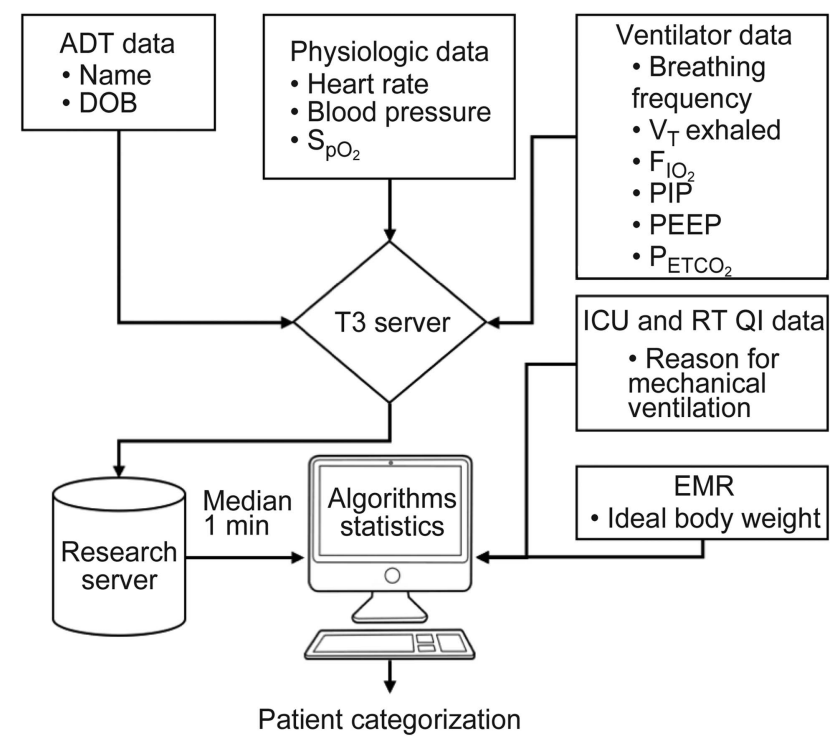

Fig. 1. Multiple data sources and flow of data from one system to another. ADT = admission, discharge, transfer; $\mathrm{DOB}=$ date of birth; PIP = peak inspiratory pressure; $\mathrm{RT}=$ respiratory therapy; $\mathrm{QI}=$ quality improvement; EMR = electronic medical record.

no categorization would be displayed. See Figure 1 for data flow from the multiple sources.

\section{Subject Categorization}

A novel method for categorizing the state of a patient undergoing mechanical ventilation summarizing a patient's condition was developed to mimic how clinicians analyze data at the bedside. Fifteen rules-based algorithms were developed that cover 3 domains: (1) ventilation, (2) oxygenation, and (3) ventilator-induced lung injury. This process involves receiving, selecting, retrieving, and categorization. Table 1 provides the details of the rules-based algorithms. The goal of subject categorization was to convey information about the subject's status from predetermined generally accepted goals of mechanical ventilation. All subject categorization is presented in percent of recorded time and chosen before analysis. None of the subject categorization was made available in real time to clinicians.

\section{Categorization of Ventilation and Oxygenation}

Categorization of ventilation and oxygenation are detailed according to generally accepted goals of mechanical ventilation within traditional definitions. ${ }^{6,12,15-22}$ Inputs such as clinical practice guidelines, standards of care, and policies provide the intent and goals of mechanical ventilation. When clinical knowledge is paired with the clinically relevant continuously available data, it is sent to the algorithms segment to be explored. Within the algorithms 


\section{Categorization in Mechanically Ventilated Pediatric Subjects}

Table 1. The 3 Domains, 15 Categories, and Rules-Based Algorithms

\begin{tabular}{|c|c|}
\hline Domains and Categories & Definition \\
\hline \multicolumn{2}{|l|}{ Ventilation } \\
\hline Acceptable ventilation score & All ventilation goals achieved \\
\hline Tachypnea & $\begin{array}{l}\leq 6 \mathrm{mo}: \mathrm{f}>55 \text { breaths } / \mathrm{min} \text {; heart rate }<160 \text { beats } / \mathrm{min} \\
7 \mathrm{mo} \text { to }<3 \text { y: } \mathrm{f}>45 \text { breaths } / \mathrm{min} \text {; heart rate }<140 \text { beats } / \mathrm{min} \\
3 \text { to }<6 \text { y: } \mathrm{f}>40 \text { breaths } / \mathrm{min} \text {; heart rate }<110 \text { beats } / \mathrm{min} \\
>6 \text { y: } \mathrm{f}>30 \text { breaths } / \mathrm{min} \text {; heart rate }<90 \text { beats } / \mathrm{min}\end{array}$ \\
\hline Severe tachypnea & $\begin{array}{l}<6 \text { mo: } \mathrm{f}>55 \text { breaths } / \mathrm{min} \text {; heart rate }>160 \text { beats } / \mathrm{min} \\
7 \text { mo to }<3 \text { y: } \mathrm{f}>45 \text { breaths } / \mathrm{min} \text {; heart rate }>140 \text { beats } / \mathrm{min} \\
3 \text { to }<6 \text { y: } \mathrm{f}>40 \text { breaths } / \mathrm{min} \text {; heart rate }>110 \text { beats } / \mathrm{min} \\
>6 \text { y: } \mathrm{f}>30 \text { breaths } / \mathrm{min} \text {; heart rate }>90 \text { beats } / \mathrm{min}\end{array}$ \\
\hline Insufficient ventilation & $\begin{array}{l}\leq 6 \mathrm{mo}: \mathrm{P}_{\mathrm{ETCO}_{2}}>55 \mathrm{~mm} \mathrm{Hg} ; \mathrm{f}>55 \text { breaths } / \mathrm{min} \text {; heart rate }>160 \text { beats } / \mathrm{min} \\
7 \mathrm{mo} \text { to }<3 \text { y: } \mathrm{P}_{\mathrm{ETCO}_{2}}>55 \mathrm{~mm} \mathrm{Hg} ; \mathrm{f}>45 \text { breaths } / \mathrm{min} \text {; heart rate }>140 \text { beats } / \mathrm{min} \\
3 \text { to }<6 \text { y: } \mathrm{P}_{\mathrm{ETCO}_{2}}>55 \mathrm{~mm} \mathrm{Hg} ; \mathrm{f}>40 \text { breaths } / \mathrm{min} \text {; heart rate }>110 \text { beats } / \mathrm{min} \\
>6 \text { y: } \mathrm{P}_{\mathrm{ETCO}_{2}}>55 \mathrm{~mm} \mathrm{Hg} ; \mathrm{f}>30 \text { breaths } / \mathrm{min} \text {; heart rate }>90 \text { beats } / \mathrm{min}\end{array}$ \\
\hline Hypoventilation & $\begin{array}{l}<6 \mathrm{mo}: \mathrm{P}_{\mathrm{ETCO}_{2}}>55 \mathrm{~mm} \mathrm{Hg} \text {; heart rate }<160 \text { beats } / \mathrm{min} \\
7 \text { mo to }<3 \text { y: } \mathrm{P}_{\mathrm{ETCO}_{2}}>55 \mathrm{~mm} \mathrm{Hg} \text {; heart rate }<140 \text { beats } / \mathrm{min} \\
3 \text { to }<6 \text { y: } \mathrm{P}_{\mathrm{ETCO}_{2}}>55 \mathrm{~mm} \mathrm{Hg} \text {; heart rate }<110 \text { beats } / \mathrm{min} \\
>6 \text { y: } \mathrm{P}_{\mathrm{ETCO}_{2}}>55 \mathrm{~mm} \mathrm{Hg} \text {; heart rate }<90 \text { beats } / \mathrm{min}\end{array}$ \\
\hline Severe hypoventilation & $\begin{array}{l}\leq 6 \mathrm{mo}: \mathrm{P}_{\mathrm{ETCO}_{2}}>55 \mathrm{~mm} \mathrm{Hg} \text {; heart rate }>160 \text { beats } / \mathrm{min} \\
7 \mathrm{mo} \text { to }<3 \text { y: } \mathrm{P}_{\mathrm{ETCO}_{2}}>55 \mathrm{~mm} \mathrm{Hg} \text {; heart rate }>140 \text { beats } / \mathrm{min} \\
3 \text { to }<6 \text { y: } \mathrm{P}_{\mathrm{ETCO}_{2}}>55 \mathrm{~mm} \mathrm{Hg} \text {; heart rate }>110 \text { beats } / \mathrm{min} \\
>6 \text { y: } \mathrm{P}_{\mathrm{ETCO}_{2}}>55 \mathrm{~mm} \mathrm{Hg} \text {; heart rate }>90 \text { beats } / \mathrm{min}\end{array}$ \\
\hline Hyperventilation & $\begin{array}{l}<6 \text { mo: } \mathrm{P}_{\mathrm{ETCO}_{2}}<35 \mathrm{~mm} \mathrm{Hg} \text {; heart rate }<160 \text { beats } / \mathrm{min} \\
7 \mathrm{mo} \text { to }<3 \text { y: } \mathrm{P}_{\mathrm{ETCO}_{2}}<35 \mathrm{~mm} \mathrm{Hg} \text {; heart rate }<140 \text { beats } / \mathrm{min} \\
3 \text { to }<6 \text { y: } \mathrm{P}_{\mathrm{ETCO}_{2}}<35 \mathrm{~mm} \mathrm{Hg} \text {; heart rate }<110 \text { beats } / \mathrm{min} \\
>6 \text { y: } \mathrm{P}_{\mathrm{ETCO}_{2}}<35 \mathrm{~mm} \mathrm{Hg} \text {; heart rate }<90 \text { beats } / \mathrm{min}\end{array}$ \\
\hline Severe hyperventilation & $\begin{array}{l}\leq 6 \mathrm{mo}: \mathrm{P}_{\mathrm{ETCO}_{2}}<35 \mathrm{~mm} \mathrm{Hg} \text {; heart rate }>160 \text { beats } / \mathrm{min} \\
7 \mathrm{mo} \text { to }<3 \text { y: } \mathrm{P}_{\mathrm{ETCO}_{2}}<35 \mathrm{~mm} \mathrm{Hg} \text {; heart rate }>140 \text { beats } / \mathrm{min} \\
3 \text { to }<6 \text { y: } \mathrm{P}_{\mathrm{ETCO}_{2}}<35 \mathrm{~mm} \mathrm{Hg} \text {; heart rate }>110 \text { beats } / \mathrm{min} \\
>6 \text { y: } \mathrm{P}_{\mathrm{ETCO}_{2}}<35 \mathrm{~mm} \mathrm{Hg} \text {; heart rate }>90 \text { beats } / \mathrm{min}\end{array}$ \\
\hline \multicolumn{2}{|r|}{$\mathrm{CO}_{2} \mathrm{LTCO}_{2}$} \\
\hline Acceptable oxygenation score & $\mathrm{S} / \mathrm{F} \geq 264 ;<328 ;>452$ \\
\hline Mild hypoxia & $\mathrm{S} / \mathrm{F} \geq 221 ;<264$ \\
\hline Moderate hypoxia & $\mathrm{S} / \mathrm{F} \geq 153 ;<221$ \\
\hline Severe hypoxia & $\mathrm{S} / \mathrm{F}<153$ \\
\hline Hyperoxia & $\mathrm{S} / \mathrm{F} \geq 328 ; \leq 452$ \\
\hline \multicolumn{2}{|l|}{ VILI } \\
\hline Barotrauma-free & $\mathrm{PIP} \leq 30$ \\
\hline Volutrauma-free & Exhaled tidal volume $>4 \mathrm{~mL} / \mathrm{kg}$ IBW; $<8 \mathrm{~mL} / \mathrm{kg} \mathrm{IBW}$ \\
\hline \multicolumn{2}{|c|}{$\begin{array}{l}\text { Units of measure for all categories were percentage of time. } \\
f=\text { breathing frequency }\end{array}$} \\
\hline \multicolumn{2}{|c|}{$\begin{array}{l}\mathrm{P}_{\mathrm{ETCO}}=\text { end-tidal carbon dioxide pressure } \\
\mathrm{S} / \mathrm{F}=\mathrm{S}_{\mathrm{PO}_{2}} / \mathrm{F}_{\mathrm{IO}} \\
\mathrm{VILI}=\text { ventilator-induced lung injury } \\
\mathrm{PIP}=\text { peak inspiratory pressure } \\
\text { IBW = ideal body weight }\end{array}$} \\
\hline
\end{tabular}

segment, previously validated data-driven algorithms were used to develop the patient categorization. Within the algorithm aggregator, the algorithms were applied to the continuous data to describe a subjects' status. Figure 2 describes how clinical knowledge paired with clinical data was leveraged to fulfill the algorithm development and implementation. The goal of this computerized method of assessment is to determine how well goals of mechanical ventilation are achieved without contributing to settings associated with ventilator-induced lung injury. Severe categories of ventilation are triggered by the cardiopulmonary interactions of abnormal ventilation. In the absence of abnormal ventilation triggers, the acceptable ventilation category was assumed. Heart rate was chosen, because it is 


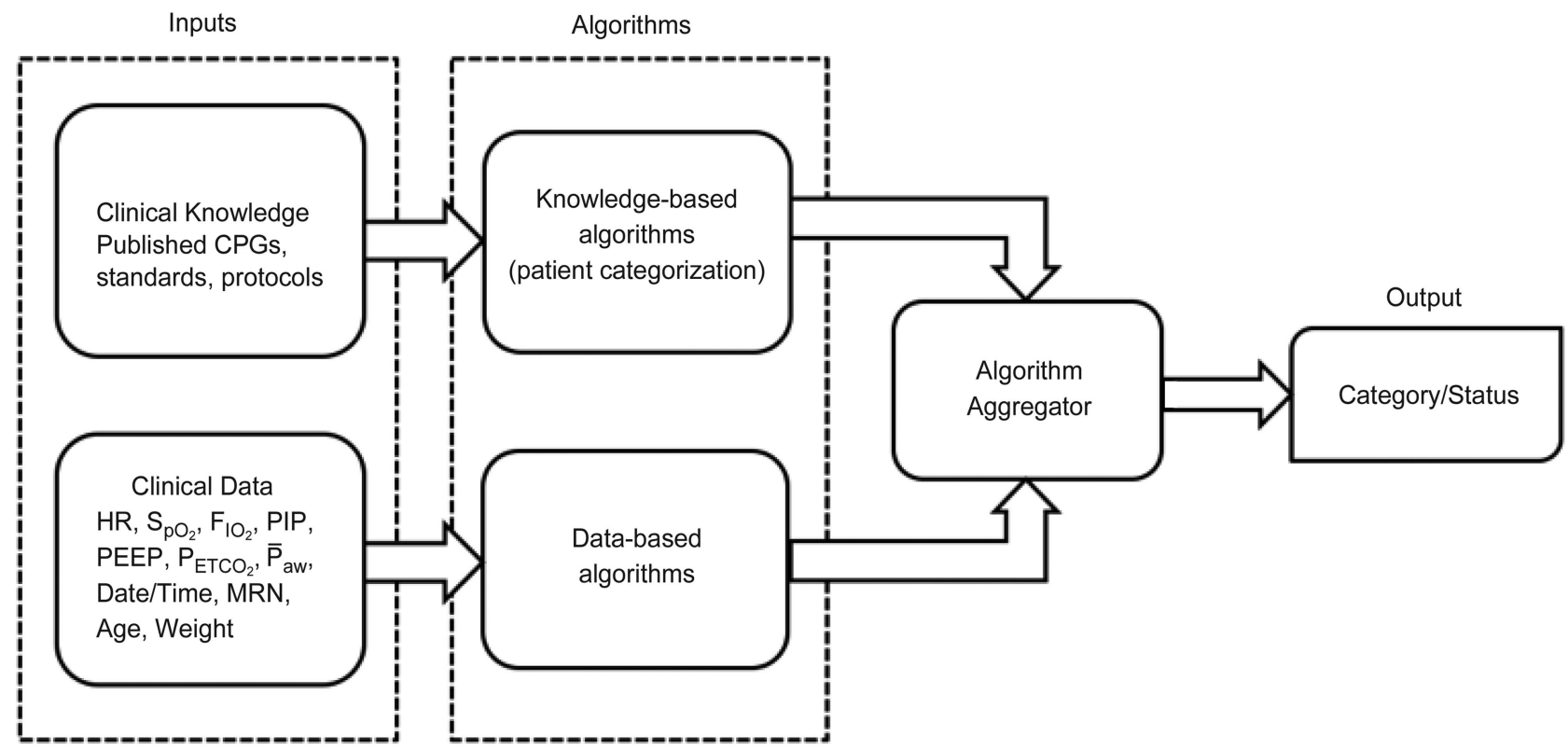

Fig. 2. How the inputs combined with the algorithms provided by an "IF" "THEN" script were programmed into the analysis software to provide an output. CPGs = clinical practice guidelines, $\mathrm{HR}=$ heart rate, $\mathrm{PIP}=$ peak inspiratory pressure, $\overline{\mathrm{P}}_{\mathrm{aw}}=$ mean airway pressure, $\mathrm{MRN}=$ medical record number.

continuously available and an indication of hemodynamic effects of the given ventilator strategy. Heart rate was only evaluated after an abnormal ventilation trigger, such as high or low end-tidal carbon dioxide pressure $\left(\mathrm{P}_{\mathrm{ETCO}_{2}}\right.$ or breathing frequency). See Table 1 for the definition of each condition.

Oxygenation categories are designed to utilize the $\mathrm{S}_{\mathrm{pO}_{2}} / \mathrm{F}_{\mathrm{IO}_{2}}$ in an attempt to add context to $\mathrm{S}_{\mathrm{pO}_{2}}$ measurement alone, as reported previously by the Pediatric Acute Lung Injury Consensus recommendations ${ }^{23}$ and validated by Tripathi et al ${ }^{24}$ and Thomas et al. ${ }^{25}$ Like heart rate, $\mathrm{S}_{\mathrm{pO}_{2}}$ and $\mathrm{F}_{\mathrm{IO}_{2}}$ are continuously available as the standard of care. In the absence of abnormal oxygenation triggers, the acceptable oxygenation category was assumed. See Table 1 for the breakdown of each oxygenation-related condition. Note that hyperoxia is excluded from negatively affecting the acceptable oxygenation category.

\section{Data/Statistical Analysis}

Data were collected from the mechanical ventilator and physiologic monitors every $5 \mathrm{~s}$. A median 1-min filter from the 12 data points/min was applied. According to Levene's test of homoscedasticity, the data are not normally distributed; therefore, we have provided medians and $25-75 \%$ interquartile range calculated from the sampled parameters according to the absolute number of measurements. JMP 12.0 (SAS Institute, Cary, North Carolina) was utilized for the statistics, categorization, and graphs. One-way analysis of variance using the nonpara- metric Kruskal-Wallis test was performed to determine significance. Comparison of pairs was performed utilizing the nonparametric Wilcoxon method of analysis. $P$ values of $<.05$ were considered significant.

\section{Calculations}

The oxygen saturation index was developed by Thomas et $\mathrm{al}^{25}$ to noninvasively assess acute lung disease and was calculated within this cohort. Although we chose to use $\mathrm{S}_{\mathrm{pO}_{2}} / \mathrm{F}_{\mathrm{IO}_{2}}$ to categorize mild, moderate, or severe hypoxia, we could have easily chosen the oxygen saturation index.

\section{Results}

\section{Subject Characteristics}

Two hundred twenty-two subjects (20\% of patients receiving mechanical ventilation) were enrolled and analyzed encompassing 1,578 $\mathrm{d}$ of mechanical ventilation from May 8, 2013 to October 31, 2015. The median (interquartile range) age was $3(0.7-12.3)$ y, median ideal body weight was 14.7 $(7.2-35) \mathrm{kg}$, and $63 \%$ of the subjects were male. See Table 2 for additional demographics by cohort. Age and weight were significantly different among groups.

Our goal was to develop a system that could obtain data from multiple devices, therefore not being device-specific. This was achieved with the exception of 2 devices. Subjects $(n=44)$ were excluded from either the ventilation or 


\section{Categorization in Mechanically Ventilated Pediatric Subjects}

Table 2. Demographics, Parameters of Oxygenation, Ventilation, Pressures, and Recording Time Parameters That Are Not Age-Dependent

\begin{tabular}{|c|c|c|c|c|c|}
\hline Parameters & Surgical & Medical & Cardiac Surgery & Cardiac & $P$ \\
\hline \multicolumn{6}{|l|}{ Demographics } \\
\hline Age, y & $3(0.85-13)$ & $5(1.1-12.5)$ & $0.11(0.01-4.5)$ & $0.7(0.11-13)$ & .02 \\
\hline Weight, $\mathrm{kg}$ & $14.7(7.1-36)$ & $17.5(9.3-36.7)$ & $5.6(3.2-18.9)$ & $7(5.3-55)$ & .01 \\
\hline$n$ & 113 & 84 & 22 & 3 & \\
\hline \multicolumn{6}{|l|}{ Oxygenation } \\
\hline $\mathrm{S}_{\mathrm{pO}_{2}}, \%$ & $98.6(97.9-99.2)$ & $98.3(97.2-99.2)$ & 98.8 (90.3-99.7) & $98.1(80.8-99.1)$ & .30 \\
\hline $\mathrm{F}_{\mathrm{IO}_{2}}, \%$ & $36.3(31.2-41.8)$ & $37.6(31.6-44)$ & $40.1(31.2-40.8)$ & $37.8(37.5-43.5)$ & .53 \\
\hline $\mathrm{S} / \mathrm{F}$ & $286(243-326)$ & $279(231-326)$ & $248(231-298)$ & $266(190-270)$ & .14 \\
\hline OSI & $3.2(2.6-4.2)$ & $3.8(2.9-4.8)$ & $3.5(2.8-4.2)$ & $4.5(3.3-6.1)$ & .064 \\
\hline \multicolumn{6}{|l|}{ Ventilation } \\
\hline $\mathrm{P}_{\mathrm{ETCO}_{2}}, \mathrm{~mm} \mathrm{Hg}$ & $42.9(40.4-46.7)$ & $41.9(37.7-45.5)$ & $34(29.8-46)$ & $44.9(44.9-45)$ & .01 \\
\hline $\mathrm{V}_{\mathrm{T}} / \mathrm{kg}$ & $7(5.8-8)$ & $7.3(6.1-8.3)$ & $8(6.8-9)$ & $7.3(5.6-7.5)$ & .064 \\
\hline \multicolumn{6}{|l|}{ Pressures } \\
\hline $\mathrm{PIP}, \mathrm{cm} \mathrm{H} \mathrm{H}_{2} \mathrm{O}$ & $18.1(15.4-21.3)$ & $19.3(15.8-22.1)$ & $19.6(18.5-22.9)$ & $23.9(19.9-26)$ & .058 \\
\hline PEEP, $\mathrm{cm} \mathrm{H}_{2} \mathrm{O}$ & $5(4.9-5.9)$ & $5.9(5-7.1)$ & $5(4.7-5)$ & $5.1(5-6.6)$ & $<.001$ \\
\hline \multicolumn{6}{|l|}{ Time } \\
\hline Recording time, $\mathrm{d}$ & $2.7(1-9.3)$ & $4.9(1.6-10)$ & $1.8(0.2-5.6)$ & $12(6.9-15.8)$ & .08 \\
\hline $\begin{array}{l}\text { Percentage recording of duration } \\
\text { of mechanical ventilation, } \%\end{array}$ & 35 & 62 & 40 & 100 & \\
\hline \multicolumn{6}{|c|}{$\begin{array}{l}\text { Data are median (interquartile range). } P \text { values are according to the Kruskal-Wallis method. } \\
\mathrm{S} / \mathrm{F}=\mathrm{S}_{\mathrm{pO}} / \mathrm{F}_{\mathrm{IO}_{2}} \\
\mathrm{OSI}=\mathrm{oxygen} \text { saturation index } \\
\mathrm{P}_{\mathrm{ETCO}}=\text { end-tidal carbon dioxide pressure } \\
\mathrm{PIP}=\text { peak inspiratory pressure } \\
\mathrm{V}_{\mathrm{T}}=\text { tidal volume }\end{array}$} \\
\hline
\end{tabular}

oxygenation assessments because either $\mathrm{P}_{\mathrm{ETCO}_{2}}$ or $\mathrm{F}_{\mathrm{IO}_{2}}$ data were missing. We isolated this missing data to the CareFusion Avea $\left(\mathrm{P}_{\mathrm{ETCO}_{2}}\right)$ and Philips V60 and Philips NM3 $\left(\mathrm{P}_{\mathrm{ETCO}_{2}}\right.$ and $\left.\mathrm{F}_{\mathrm{IO}_{2}}\right)$. Due to a driver software conflict between Philips and CareFusion, $\mathrm{P}_{\mathrm{ETCO}_{2}}$, although measured and displayed, was not provided in the Health Level 7 data feed. Therefore, ventilation categorization could not be performed in these subjects $(n=40)$, but oxygenation categorization could be performed. The Philips V60 does not measure $\mathrm{F}_{\mathrm{IO}_{2}}$ or $\mathrm{P}_{\mathrm{ETCO}}$; therefore, no oxygenation or ventilation categorization could be performed $(n=2)$. The Philips NM3 measures all parameters except for $\mathrm{F}_{\mathrm{IO}_{2}}$. No oxygenation categorization was provided in those subjects $(n=2)$.

\section{Ventilation Categories}

The median (interquartile range) acceptable ventilation score was $84.6 \%(69.4-95.3 \%)$ for the entire cohort. Acceptable ventilation was not significantly different among the surgical, medical, and cardiac cohorts; however, there was a significant difference between the cardiac surgery and general surgery groups $(P=.03)$. See Table 3 for details. Figure 3 describes the 6 abnormal ventilation categories organized by cohort.

\section{Oxygenation Categories}

The median (interquartile range) acceptable oxygenation score was 70.1\% (27.2-95.3\%) among all mechanically ventilated subjects. There were no significant differences among cohorts. See Table 3 for details. Figure 4 describes the 4 categories of abnormal oxygenation organized by cohort.

\section{Heart Rate, Respiratory Rate, and Ventilation Index}

Heart rate, breathing frequency, spontaneous breathing frequency, and modified ventilation index are presented in 4 age subcategories and by reasons for mechanical ventilation (see Table 4). All data are presented as medians and interquartile ranges.

Heart rate was significantly higher in the cardiac surgery cohort when compared with the general surgery cohort $(P=.01)$ in the $\leq 6$-month subcategory. Heart rate was significantly lower in the cardiac surgery cohort than in the medical cohort in the $>6 \mathrm{y}$ of age subcategory.

Breathing frequency was significantly higher in the surgical cohort as compared with the medical cohort in both the $\leq 6$-month $(P=.033)$ and 7 months to $<3$ y of age 


\section{Categorization in Mechanically Ventilated Pediatric Subjects}

Table 3. Summary Results of the 3 General Domains by Cohort

\begin{tabular}{lcccc}
\hline \hline \multicolumn{1}{c}{ Parameters } & Surgical & Medical & Cardiac Surgery & Cardiac \\
\hline Acceptable ventilation score, \% & $88(69-96)^{*}$ & $84(70-94)$ & $77(14-85)^{*}$ & $83(77-90)$ \\
Acceptable oxygenation score, \% & $77(32-97)$ & $61(26-94)$ & $39(4-89)$ & .033 \\
VILI, \% & & & & $48(4-71)$ \\
Barotrauma-free score & $100(99-100)$ & $100(99-100)$ & 100 & .13 \\
Volutrauma-free score & $65(24-91)$ & $51(18-83)$ & $49(34-71)$ & $59(85-100)$ \\
\end{tabular}

Data are median (interquartile range). $P$ values are according to the Kruskal-Wallis method.

* $P$ value comparisons using the Wilcoxon method.

VILI = ventilator-induced lung injury

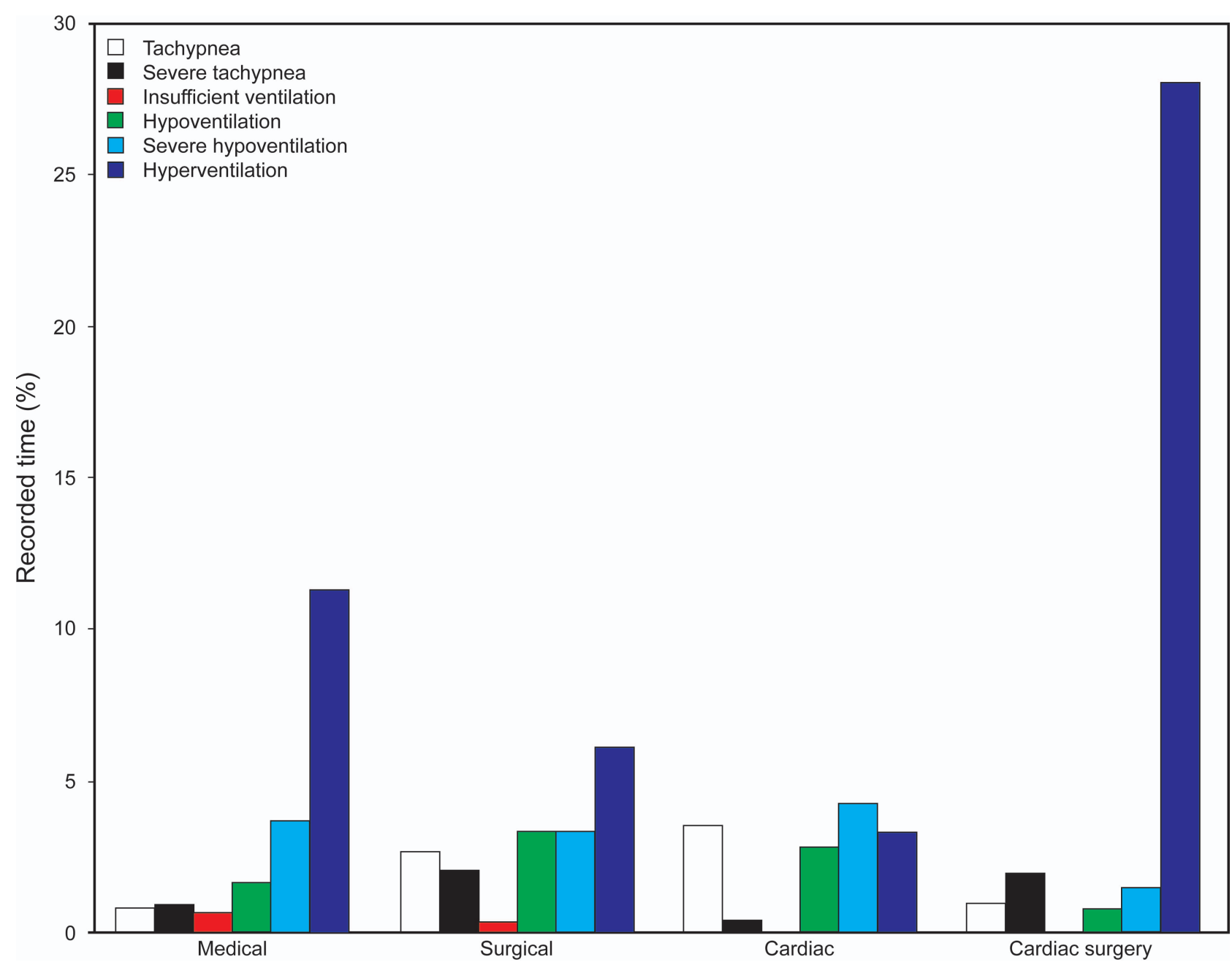

Fig. 3. Abnormal categories of ventilation by subject cohort. The bars represent the percentage of time spent within each category.

$(P=.01)$ subcategories. The modified ventilation index was significantly higher in the surgical cohort when compared with the medical cohort $(P=.003)$.

\section{Ventilator-Induced Lung Injury}

Ventilator-induced lung injury parameters were broken down into 2 categories, barotrauma-free and volutrauma-free states. Median (interquartile range) percentage of recorded time spent in a potential barotrauma-free state was $100 \%$ (99.9-100\%) among all mechanical ventilation subjects. There were no significant differences among cohorts of subjects. The median (interquartile range) percentage of recorded time spent in a potential volutrauma-free state was $56.1 \%(24.8-87.6 \%)$ among all mechanical ventilation subjects. 


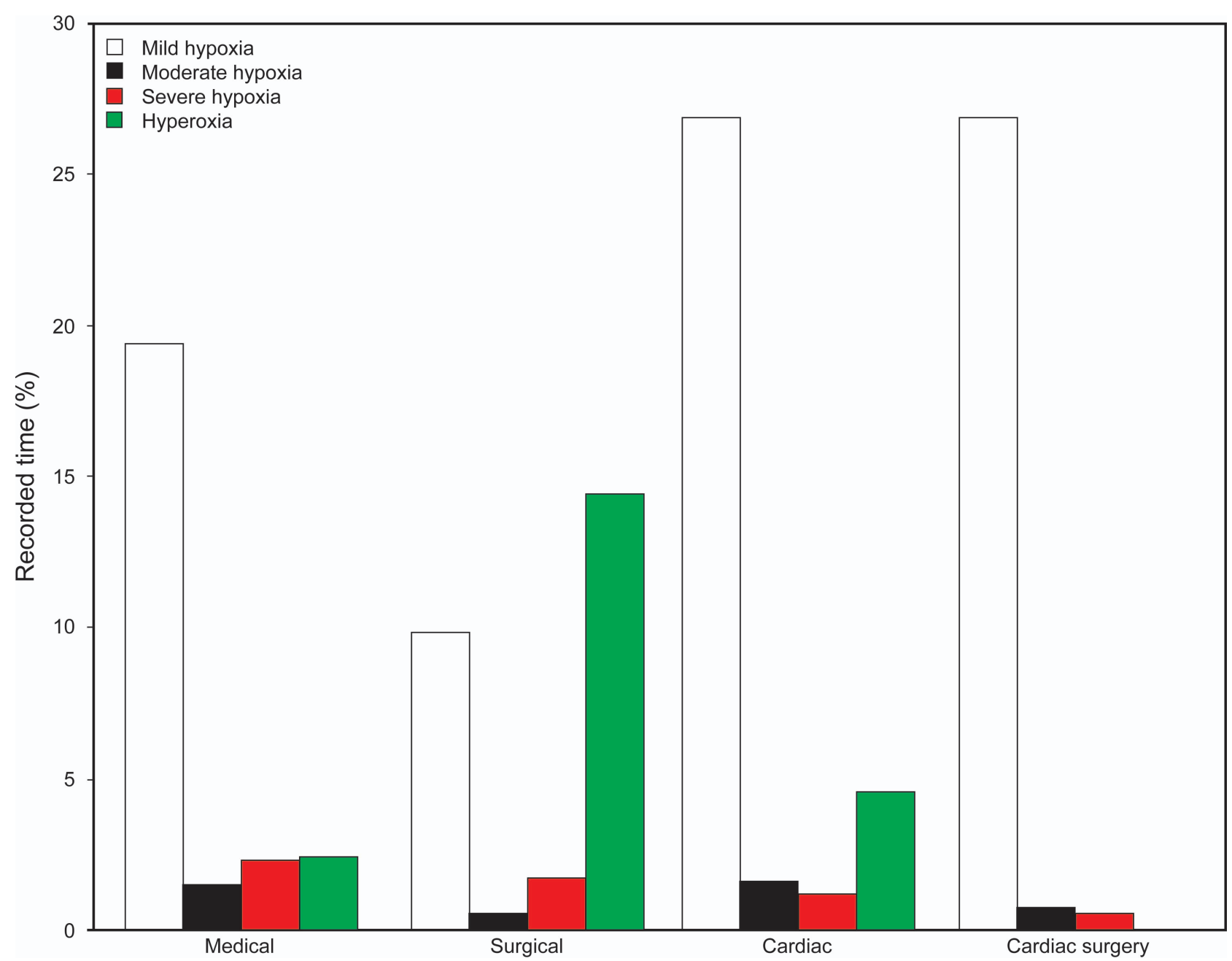

Fig. 4. Abnormal categories of oxygenation by subject cohort. The bars represent the percentage of time spent within each category.

\section{Discussion}

To our knowledge, this is the first description in the literature of the utility and application of a patient categorization system employing multiple sources of data to be used as a benchmark for future quality improvement interventions. Our findings represent an objective measure of opportunities within our own practice to discuss and potentially implement solutions for better quality patient care. Our hope is that positive trends in goal obtainment (control) will lead to improved outcomes or that negative trends in goal obtainment (lack of control) will serve as an early warning system before a negative patient outcome occurs.

\section{Goals of Mechanical Ventilation}

The quality of mechanical ventilation is often based on outcomes such as length of stay, time to liberation, venti- lator-free days, ventilator-associated pneumonia, incidences of pneumothoraces, or brain or airway injury, yet these quality measures are end results or retrospective in nature. Although certainly not exhaustive, our effort was to capture generally accepted goals of mechanical ventilation while attempting to be as lung-protective as possible based on current evidence. Often, set goals of mechanical ventilation are ideal but not real, meaning that we have great intentions but rarely measure how well we meet those intentions. Measuring the impact of these goals on mechanical ventilation outcomes can be challenging. When clinicians find patients outside of the goals, they often correct the situation without any context for the length of time the patient may have been outside of the goal. Due to alarm fatigue, we often set our alarms or alerts broadly so as to only notify clinicians of lifealtering events. The goal of $100 \%$ compliance may not be obtainable as certain situation are outside of the clinician's control. However, leveraging a computerized 


\section{Categorization in Mechanically Ventilated Pediatric Subjects}

Table 4. Results by Age Category and Cohort

\begin{tabular}{|c|c|c|c|c|c|}
\hline Parameters and Subgroups & Surgical & Medical & Cardiac Surgery & Cardiac & $P$ \\
\hline \multicolumn{6}{|l|}{ Heart rate beats/min } \\
\hline$\leq 6 \mathrm{mo}$ & $127.6(114.3-132.8)^{*}$ & $122.2(114.3-132.8)$ & $147.1(133.9-158)^{*}$ & 147 & .01 \\
\hline $7 \mathrm{mo}$ to $<3 \mathrm{y}$ & $111.4(22.56,12)$ & $116.5(16.5,19)$ & $145.2(14.7,7)$ & $100(-, 1)$ & .08 \\
\hline$>3$ to $<6 y$ & $110(96.9-123)$ & $113.4(108.2-124.2)$ & ND & ND & .40 \\
\hline$>6 y$ & $95.1(77.5-107.3)$ & $102(90.6-119.2)^{*}$ & $67(61.5-85)^{*}$ & 108.1 & .006 \\
\hline \multicolumn{6}{|l|}{ Breathing frequency beats/min } \\
\hline$<6$ mo & $40.4(23.5-48.9)^{*}$ & $25.2(21.3-32.5)^{*}$ & $25.2(23.4-32.5)$ & 24.8 & .031 \\
\hline$\geq 7$ mo to $<3 \mathrm{y}$ & $24(21.5-27.5)^{*}$ & $21.3(20.8-22.6)^{*}$ & 22.2 & 27.8 & .01 \\
\hline$>3$ to $<6 y$ & $23(20.1-25.3)$ & $20.7(16.3-23.4)$ & ND & ND & .13 \\
\hline$>6 y$ & $15.5(13.5-19.1)$ & $16.2(14-22)$ & $15.6(12-16)$ & 21.2 & .32 \\
\hline \multicolumn{6}{|c|}{ Spontaneous breathing frequency beats/min } \\
\hline$<6$ mo & $27.4(15.2-44)$ & $20.2(14.3-25.2)$ & $24.5(15.9-32.5)$ & 20.1 & .36 \\
\hline$>7 \mathrm{mo}$ to $<3 \mathrm{y}$ & $17.4(9.9-22.4)$ & $15(8.4-20.6)$ & 17.9 & 25 & .35 \\
\hline$>3$ to $<6$ y & $14.1(12.5-19.5)$ & $11.1(7.6-18.8)$ & ND & ND & .35 \\
\hline$\geq 6 \mathrm{y}$ & $12.1(7.7-17.5)$ & $13.5(8.7-19.6)$ & $10(4.8-15.3)$ & 10.9 & .46 \\
\hline
\end{tabular}

Data are median (interquartile range). $P$ values are according to the Kruskal-Wallis method.

* $P$ value comparisons using Wilcoxon method.

system to identify outliers to the standard of care will improve our MV quality.

\section{Limitations}

We were not able to obtain complete recordings of every mechanically ventilated patient in our 2 ICUs because the number of devices (Intellibridge EC10) limited our ability to capture these data. Therefore, we were not able to draw outcome conclusions based on our patient categorization and instead report our findings as percentage of recorded time. Since the beginning of our study, we have purchased enough devices to connect every ventilator and will be able to report clinical outcomes in the near future.

\section{Disease-Specific Goals}

Although we did not develop disease- or patient-specific goals of mechanical ventilation, this clearly needs to be the next step in our program's progression. We set out to determine the feasibility of our system of care by utilizing broad goals that are applicable to the majority of our patients receiving mechanical ventilation. One limitation of not setting disease- or patient-specific goals is the fact they may actually disguise the best care. For example, to provide neuro-protective ventilation, one may target a $\mathrm{P}_{\mathrm{ETCO}_{2}}$ of $30-40 \mathrm{~mm} \mathrm{Hg}$ to ensure a normal $\mathrm{P}_{\mathrm{aCO}}$ of $35-45 \mathrm{~mm} \mathrm{Hg}$, or in a patient with severe pediatric ARDS, a tidal volume of 3-6 mL/kg may be the more appropriate target. However, because the purpose of the presented investigation was to set and monitor boundaries in which the majority of patients should be maintained, this provides an adequate system.

\section{Oxygenation Categories}

The oxygenation categories are an area in which there is much debate. The majority of pediatric patients are placed on mechanical ventilation for hypoxic respiratory failure, so it is not surprising that mild hypoxemia is a common occurrence. Some even employ a strategy of permissive hypoxemia to avoid lung injury. Normal gas exchange should be a goal of mechanical ventilation except when attempting to achieve normal gas exchange violates lungprotective strategies. Normal gas exchange should be secondary to $\mathrm{F}_{\mathrm{IO}_{2}}$, tidal volume, and pressure limits.

\section{Intraoperability}

There are several limitations to this method that we have discovered along the way. One is the ability to capture all of the data from devices within our ICU. Not all devices provide data in the same language which has limited our ability analyze. As mentioned, we had to exclude some patient categorizations due to the lack of available data. We narrowed this down to a Philips driver and CareFusion ventilator software compatibility issue, which we were unable to resolve.

\section{Labeling of Parameters}

Health Level 7 is a set of international standards for the transfer of clinical and administrative data between soft- 


\section{Categorization in Mechanically Ventilated Pediatric Subjects}

ware applications. Although this standardized way of communicating is helpful at moving large amounts of data in an efficient way, there are no universal definitions of parameters within health care. For example, one ventilator can send out data in Health Level 7 format and label it PIP for peak inspiratory pressure, and another ventilator can send out the same parameter but label it PAW for peak airway pressure, making it difficult to find, capture, or track these parameters within a large database. This required a manual process to monitor, particularly when utilizing different ventilators or monitors. We have created a code library for each of the ventilators within our institution and will create a program to align like parameters in the near future to resolve and ensure data integrity.

\section{Severe Categories}

Historically, severe categories were often based on how far a value was above or below the given monitored parameter. Some would use SD values to determine this range of high (or low) to severely high (or low). However, when critically thinking of how most clinicians obtain and analyze data, they often look for relationships within multiple organ systems. One relationship that most focus on is cardiopulmonary interaction. We have a term in pediatrics of "comfortably tachypneic." This means that the patient is breathing fast, but no other organ systems are showing signs or symptoms of distress. In today's electronic world, we can come closer and closer to being able to retrieve and analyze data similar to the best clinician within a given practice. This may allow future utilization of expert opinion on a minute by minute basis.

\section{Conclusions}

We demonstrate the first patient categorization system that utilizes multiple data sources and calculations to determine a patient status and indicator of mechanical ventilation quality. Further research is needed to determine whether interventions such as visual display of variance from goal and patient categorization summaries can improve patient outcomes by providing clinicians with useful and objective information.

\section{ACKNOWLEDGMENT}

We acknowledge the support and assistance of the respiratory therapist, physicians, and nurses in the medical surgical ICU and cardiac ICU of Boston Children's Hospital. We also thank Drs Beckett, Becker, and Kuperman for assistance and support by serving on the dissertation committee for BW.

\section{REFERENCES}

1. Newth CJ, Venkataraman S, Willson DF, Meert KL, Harrison R, Dean JM, et al. Weaning and extubation readiness in pediatric patients. Pediatr Crit Care Med 2009;10(1):1-11.
2. Angus DC, Linde-Zwirble WT, Clermont G, Griffin MF, Clark RH. Epidemiology of neonatal respiratory failure in the United States: projections from California and New York. Am J Respir Crit Care Med 2001;164(7):1154-1160.

3. Volakli EA, Sdougka M, Drossou-Agakidou V, Emporiadou M, Reizoglou M, Giala M. Short-term and long-term mortality following pediatric intensive care. Pediatr Int 2012;54(2):248-255.

4. Wolfler A, Calderoni E, Ottonello G, Conti G, Baroncini S, Santuz $\mathrm{P}$, et al. Daily practice of mechanical ventilation in Italian pediatric intensive care units: a prospective survey. Pediatr Crit Care Med 2011;12(2):141-146

5. Berger TM, Fontana M, Stocker M. The journey towards lung protective respiratory support in preterm neonates. Neonatology 2013; 104(4):265-274.

6. Determann RM, Royakkers A, Wolthuis EK, Vlaar AP, Choi G, Paulus F, et al. Ventilation with lower tidal volumes as compared with conventional tidal volumes for patients without acute lung injury: a preventive randomized controlled trial. Crit Care 2010;14(1):R1.

7. Randolph AG, Wypij D, Venkataraman ST, Hanson JH, Gedeit RG, Meert KL, et al. Effect of mechanical ventilator weaning protocols on respiratory outcomes in infants and children: a randomized controlled trial. JAMA 2002;288(20):2561-2568.

8. Restrepo RD, Fortenberry JD, Spainhour C, Stockwell J, Goodfellow LT. Protocol-driven ventilator management in children: comparison to nonprotocol care. J Intensive Care Med 2004;19(5):274-284.

9. Schultz MJ. Lung-protective mechanical ventilation with lower tidal volumes in patients not suffering from acute lung injury: a review of clinical studies. Med Sci Monit 2008;14(2):RA22-RA26.

10. Schultz TR, Lin RJ, Watzman HM, Durning SM, Hales R, Woodson $\mathrm{A}$, et al. Weaning children from mechanical ventilation: a prospective randomized trial of protocol-directed versus physician-directed weaning. Respir Care 2001;46(8):772-782.

11. Serpa Neto A, Cardoso SO, Manetta JA, Pereira VG, Espósito DC, Pasqualucci Mde O, et al. Association between use of lung-protective ventilation with lower tidal volumes and clinical outcomes among patients without acute respiratory distress syndrome: a meta-analysis. JAMA 2012;308(16):1651-1659.

12. Wolthuis EK, Choi G, Dessing MC, Bresser P, Lutter R, Dzoljic M, et al. Mechanical ventilation with lower tidal volumes and positive end-expiratory pressure prevents pulmonary inflammation in patients without preexisting lung injury. Anesthesiology 2008;108(1):46-54.

13. Wood G, MacLeod B, Moffatt S. Weaning from mechanical ventilation: physician-directed vs a respiratory-therapist-directed protocol. Respir Care 1995;40(3):219-224.

14. The Acute Respiratory Distress Syndrome Network. Ventilation with lower tidal volumes as compared with traditional tidal volumes for acute lung injury and the acute respiratory distress syndrome. New Engl J Med 2000;342(18):1301-1308.

15. Plani N, Becker P, van Aswegen $\mathrm{H}$. The use of a weaning and extubation protocol to facilitate effective weaning and extubation from mechanical ventilation in patients suffering from traumatic injuries: a non-randomized experimental trial comparing a prospective to retrospective cohort. Physiother Theory Pract 2013;29(3):211-221.

16. Lellouche F, Lipes J. Prophylactic protective ventilation: lower tidal volumes for all critically ill patients? Intensive Care Med 2013; 39(1):6-15

17. Gupta P, Giehler K, Walters RW, Meyerink K, Modrykamien AM. The effect of a mechanical ventilation discontinuation protocol in patients with simple and difficult weaning: impact on clinical outcomes. Respir Care 2014;59(2):170-177.

18. Teixeira C, Maccari JG, Vieira SR, Oliveira RP, Savi A, Machado AS, et al. Impact of a mechanical ventilation weaning protocol on the extubation failure rate in difficult-to-wean patients. J Bras Pneumol 2012;38(3):364-371. 


\section{Categorization in Mechanically Ventilated Pediatric Subjects}

19. Silva CS, Timenetsky KT, Taniguchi C, Calegaro S, Azevedo CS, Stus $\mathrm{R}$, et al. Low mechanical ventilation times and reintubation rates associated with a specific weaning protocol in an intensive care unit setting: a retrospective study. Clinics 2012;67(9):995-1000.

20. Racca F, Bonati M, Del Sorbo L, Berta G, Sequi M, Capello EC, et al. Invasive and non-invasive long-term mechanical ventilation in Italian children. Minerva Anestesiol 2011;77(9):892-901.

21. Caprotta G, Crotti PG, Frydman J. Tracheostomy and mechanical ventilation weaning in children affected by respiratory virus according to a weaning protocol in a pediatric intensive care unit in Argentina: an observational restrospective trial. Ital J Pediatr 2011;37:5.

22. Robertson TE, Sona C, Schallom L, Buckles M, Cracchiolo L, Schuerer D, et al. Improved extubation rates and earlier liberation from mechanical ventilation with implementation of a daily spontaneous-breathing trial protocol. J Am Coll Surg 2008;206(3):489-495.

23. Pediatric Acute Lung Injury Consensus Conference Group. Pediatric acute respiratory distress syndrome: consensus recommendations from the Pediatric Acute Lung Injury Consensus Conference. Pediatr Crit Care Med 2015;16(5):428-439

24. Tripathi RS, Blum JM, Rosenberg AL, Tremper KK. Pulse oximetry saturation to fraction inspired oxygen ratio as a measure of hypoxia under general anesthesia and the influence of positive end-expiratory pressure. J Crit Care 2010;25(3):542.e9-13.

25. Thomas NJ, Shaffer ML, Willson DF, Shih MC, Curley MA. Defining acute lung disease in children with the oxygenation saturation index. Pediatr Crit Care Med 2010;11(1):12-17.

This article is approved for Continuing Respiratory Care Education credit. For information and to obtain your CRCE

(free to AARC members) visit 